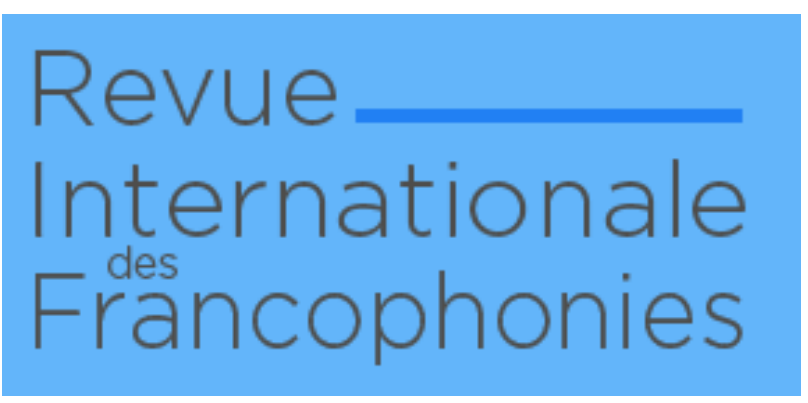

\title{
Varietas delectat ? Les rapports entre l’État hongrois et les Églises en Hongrie
}

\section{Peter Kruzslicz}

Les rapports entre un État et les Églises établies et fonctionnant sur le territoire national ou regroupant les nationaux et entrant ainsi en relation avec la souveraineté nationale, peuvent faire l'objet d'études sous plusieurs aspects. Le présent article porte sur les rapports entre l'État hongrois et les Églises en Hongrie pour les étudier sous l'aspect du droit, notamment du droit constitutionnel dans l'objectif également d'avancer des éléments qui seraient pertinents pour une comparaison avec d'autres régimes juridiques réglant ces rapports dans d'autres contextes nationaux. En constat de départ à ce travail non seulement descriptif mais également analytique, il est précisé que les Églises et les confessions religieuses autour desquelles elles se construisent, sont à qualifier à plusieurs niveaux et sous plusieurs aspects, même dans une approche purement juridique, au sein d'une société nationale : si elles sont des constructions institutionnelles, personnes juridiques entrant ainsi en rapports règlementés par le droit avec l'État; elles constituent également, dans leur cadre institutionnel mais également au-delà d'une telle construction, des communautés spécifiques, soudées par une identité confessionnelle et religieuse, à laquelle l'État peut, toujours par le droit, confier des missions sociales ou au contraire, il peut leur interdire l'accomplissement de telles missions qualifiées publiques; enfin, elles portent des valeurs tout autant que des intérêts qu'elle représentent, et qui peuvent être articulés et agrégés dans les fondements de la Nation tout autant que ceux-ci peuvent être juridiquement définis justement pour les y exclure. Les Églises, institutionnalisées, constituant des communautés, représentant des valeurs et des intérêts sont donc l'objet mais également le sujet des règlementations juridiques, et notamment constitutionnelles que l'État produit ou qui sont même inspirées par ces institutions et communautés confessionnelles. L'exemple de la Hongrie est enrichissant dans l'étude d'une telle problématique en raison de la diversité - la variété - dont témoignent à la fois les règlementations juridiques qui au fil du temps et en fonction des contextes, justement dans les différents aspects ci-dessus mentionnés, se sont intéressées aux Églises, mais aussi très simplement en raison de la diversité de ces Églises qui se sont institués dans un contexte centre européen à la croisée des cultures, des tendances idéologiques ou purement des valeurs et des intérêts. Ainsi l'analyse présente après une introduction rappelant les éléments essentiels pour une bonne compréhension du contexte mais également pour exposer l'actualité et l'intérêt de l'analyse et sa méthode spécifique, d'abord, la diversité des règlementations dans le temps à travers de deux exemples précis, puis, l'appréhension juridique et constitutionnelle plus actuelle de la diversité des Églises par l'État. Les deux parties sont ainsi cohérentes et pertinentes permettant d'analyser, conformément aux choix précédents, une approche institutionnelle engagée à la fin du $\mathrm{XIX}^{\mathrm{e}}$ siècle, une perception purement idéologique des communautés confessionnelles pendant l'époque du socialisme, puis, après un changement radical lors de la transition dite démocratique, d'abord, une libéralisation, puis, une vision plus marquée par les valeurs et les intérêts portés par les Églises. L'étude porte donc sur les lois libérales de 1894 et de 1895, puis, sur la politique socialiste vis-àvis des Églises, enfin, sur les deux législations aux caractéristiques très opposées, adoptées après le changement de régime et plus récemment, soulevant de nombreux questionnements juridiques. Pour la comparaison à laquelle l'étude souhaite soumettre les régimes hongrois respectifs, elle souligne le fait que les Églises et notamment les religions autour desquelles elles se construisent, sont des éléments importants d'une culture nationale, dans une approche juridique, il est donc nécessaire de les analyser en tant que telles pour bien comprendre leur place et leur rôle en droit constitutionnel. 
Relations between a State and the Churches established on national territory or bringing together national citizens and entering in contact as such with national sovereignty, can be issue for research in several aspects. This article is studying the relations between the Hungarian State and Churches in Hungary in order to give a legal, especially constitutional analysis of the topic, also with the aim that some elements could be explained that are relevant for a comparative study with other national regimes ruling on those relations in different national contexts. At the origin of such a study not only descriptive but also analytic, it is to be clarified that Churches and confessions for which they are institutionalized, can be qualified, even under a purely legal approach, at different level in the framework of a national society: they are surely institutional structures, legal bodies that are entering in legal relations with the State; but they are also constituting special communities, cemented by a confessional or religious identity, for which the State can attribute, also by legal rules, social missions, or, in the contrary, can prohibit for them the accomplishment of such functions qualified as public ones; finally, they articulate values and also interests and those can be aggregated in the fundaments of the Nation but also they can be defined in order to exclude them from public sphere. Churches, institutionalized, constituting communities, representing values and interests, are for national legal and especially constitutional regulations, a topic but also actors: State acts on the Churches, but it is also inspired when ruling by those institutions and confessional communities. Hungarian example is interesting for a further study of that problematic because of the diversity - the variety - that is apparent as much as in legal regulations about Churches, acted in different periods and in divers contexts, especially as regards to the above mentioned aspects, but also, simply, because of the diversity of Churches, implemented in a central European context at the meeting point between cultures, ideological tendencies or purely values and interests. So, the analysis describes after an introduction about the most important elements that should be exposed for a better comprehension of the context and also about the actuality and the relevance of the study as about its specific method, first, the diversity of regulation in the timeframe with two specific examples, second, the more actual legal and constitutional apprehension of the Hungarian State on Churches. The two parts are coherent and pertinent opening the way for a comprehensive analysis, in conformity of the previously mentioned choices, about the institutional approach made by the acts adopted at the end of the $19^{\text {th }}$ century, about a purely ideological perception of confessional communities during the socialist period, then, after a radical change with the so-called democratic transition, a liberalization, then, a vision more focused on values and interests represented by the Churches. So, the study is about the liberal legislation of 1894 and 1895, then, about socialist politics on Churches, finally, about the two regulations with very different characteristics, adopted after the change of regime and more recently, subject to numerous legal critics. As for the comparison that the study would like to make possible for the different Hungarian regulations, it emphasize the fact that Churches and especially religions for which those are established, are important element for national culture, in a legal approach, it is hence necessary to analyze them as such in order to have a better knowledge about their place and role in constitutional law.

\section{Mots-clés}

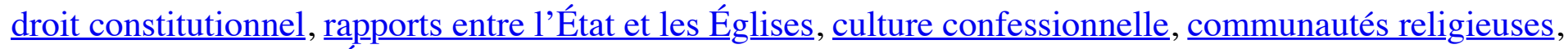
$\underline{\text { fonctions sociales des Églises }}$

\section{Keywords}

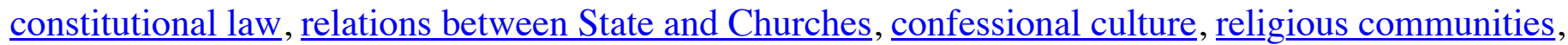
social functions of Churches

\section{Table des matières}

- I. La diversité des régimes juridiques dans l'histoire de la Hongrie

○ I.1. Les lois libérales de 1894 et de 1895 
- I.2. La politique socialiste

- II. La diversité des Églises en Hongrie

- II.1. La politique contemporaine

- II.2. La législation actuelle à l'épreuve de la CEDH

\section{Texte intégral}

\section{(Imprimer le texte intégral)}

\section{« Reddite quæ sont Cæsaris Cæsari, et quæ sunt Dei Deo »}

« Regnum meum non est de hoc mundo si ex hoc mundo esset regnum meum ministri mei »

Aux yeux, habitués à une séparation claire et nette entre l'État et l'Église, d'un lecteur avisé en droit public, l'exemple hongrois en la matière, notamment en cherchant à définir juridiquement, voire même constitutionnellement, des rapports étroits entre l'État hongrois et les Églises en Hongrie, peut paraître extraordinaire, pour ne pas dire, extravagant. Cet exemple se lit, bien entendu, dans un contexte particulier, aussi extraordinaire que le régime constitutionnel de ces rapports qui y est émergé, mais il nous enseigne, notamment à l'épreuve de la comparaison de telles dispositions avec d'autres, les fondements qui peuvent guider la régularisation constitutionnelle en la matière 1 .

Il est donc pertinent, avant même de définir et de problématiser notre sujet, de présenter d'une manière aussi succincte que complète, le contexte, notamment à travers de l'historique des rapports entre l'État hongrois et les Églises en Hongrie. Mais commençons-le par l'actuel, en rappelant les termes du préambule constitutionnel en vigueur dont le libellé commence par la citation du premier vers de l'hymne national : «Bénis les Hongrois, ô Seigneur »; et on y lit dans la suite : nous, les Hongrois, « sommes fiers que notre roi Saint Étienne ait placé l'État hongrois sur des fondations solides et qu'il ait fait entrer notre patrie dans l'Europe chrétienne » (Déclaration de foi nationale de la Loi fondamentale). L'enjeu constitutionnel dans un texte où le christianisme est aussi présent, est tout de suite aux mises (CsinkFröhilich, 2012, 43).

Il est à comprendre que dans la narrative historique de la Hongrie actuelle, consacrée par la Loi fondamentale, adoptée le 25 avril 2011 par l'Assemblée nationale, agissant en sa qualité du pouvoir constituant, la chrétienté reste un socle important. Et si cela est dû avant tout au rôle que la conversion au christianisme occidental a joué dans la fondation de l'État hongrois, elle est également soulignée pour sa fonction jouée dans la préservation, à travers de l'histoire, de l'unité nationale (Pákozdi, 2012, 39) ; le sixième considérant du préambule constitutionnel déclare ainsi : « nous reconnaissons le rôle du christianisme dans la préservation de la Nation », tout en ajoutant, « Nous respectons les différentes traditions religieuses de notre pays » (Déclaration de foi nationale de la Loi fondamentale). L'État et le christianisme ainsi des Églises qui le représentent, se mélangent dans ce récit avec des conséquences constitutionnelles (Jakab, 2011, 9).

Mais avant de voir ces conséquences, il est à préciser quel contexte, notamment historique permet de manifester une telle extravagance au constituant hongrois, se réunissant en début de la seconde décennie de ce deuxième millénaire - après Jésus-Christ - pour adopter une constitution moderne dans l'ère postmoderne ? Autrement dit, si les références historiques peuvent être exactes : la conversion au christianisme occidental joua un rôle sûrement important dans la consolidation du Royaume de Hongrie, il y a plus de mille ans, et l'attachement au christianisme, par la suite, fut un élément essentiel de la cohésion nationale hongroise au cours d'une histoire tourmentée, marquée par des guerres de résistance et d'indépendance ; quel peut être son apport dans nos jours ? (Varga Zs., 2016, 85)

Dans l'histoire de la Hongrie, l'élément originaire, en quelque sorte le point de départ, étudié également sous l'aspect du droit constitutionnel, car il s'agit parallèlement de la fondation d'un État médiéval : le 
Royaume de Hongrie, fut la conversion à l'Église catholique romaine, décision prise par le roi Étienne, couronnée ainsi par la Sainte Couronne, obtenue du pape Sylvestre II à l'an 1000. Nous voyons aisément, dans ce contexte du Moyen-Âge féodal, le rôle de l'Église et du christianisme à intégrer à une société en voie de construction identitaire et étatique, dans la consolidation d'un royaume où le roi règne par la grâce du Dieu, représenté, institutionnellement, par l'Église catholique en Europe. La légitimité d'un nouvel État devait être corroborée par l'approbation ecclésiastique.

Dans le cas de la Hongrie, cette légitimité obtenue par l'accord de l'Église qui l'avait conditionnée à une soumission à son cadre institutionnel, est encore plus importante que pour d'autres constructions étatiques qui s'étaient consolidées à cette même époque en Europe. Et par sa géographie, se situant dans le bassin des Carpates à la croisée de l'Église orientale et occidentale, et par son passé où des invasions régulières des troupes hongroises avaient bouleversé les royaumes chrétiens et féodaux déjà constitués, ce passage au christianisme occidental fut encore plus symbolique, marquant un choix délibéré d'appartenance à une Europe occidentale, un choix qui revenait, par la suite, souvent dans l'histoire de la Hongrie jusqu'au passé le plus récent, et qui est donc également identitaire.

La fondation de l'État hongrois coïncide donc d'une manière fortement marquée, avec la conversion au catholicisme, c'est l'élément historique repris par la Loi fondamentale, constitution hongroise en vigueur. Mais si à l'origine, la chrétienté et l'Église catholique fussent si importante : les premiers rois de la Hongrie sont, pour la plupart ainsi que pour d'autres membres de la famille royale de l'époque, vénérés comme des saints par l'Église jusqu'aujourd'hui, quelles seraient les conséquences pour une république contemporaine appartenant incontestablement à l'Europe par ses engagements aussi bien politiques que juridiques? Par quel apport ces fondements devraient déterminer l'État actuel sur le plan institutionnel mais également au niveau des valeurs?

Si quelques hésitations faisaient vaciller la politique hongroise médiévale jusqu'aux treizième et quatorzième siècles entre les Églises romaine et byzantine, après l'affaiblissement de cette dernière, l'appartenance à la première fut définitive. Et c'est justement la résistance face à l'Empire ottomane, occupant l'orient, qui avait renforcé l'importance de l'appartenance chrétienne de la Hongrie sur le plan politique et par conséquent sur le plan constitutionnel. Le sentiment de défendre l'Europe chrétienne face à la menace ottomane, musulmane fut le ciment de l'organisation politique de la première nation, composée encore uniquement par l'aristocratie et le clergé à l'aube du quinzième siècle ainsi qu'en témoigne les premiers auteurs en droit public de l'époque (Csehi-Szabó-Schanda-Varga Zs., 2015, 52).

En effet, la défense d'une Europe chrétienne revenait très concrètement à la charge des rois de la Hongrie qui affaiblis par de nombreux phénomènes, pour rassembler le mieux leurs troupes, comptaient renforcer un tel sentiment de résistance dans la défense de l'État hongrois mais également de l'Église catholique. Les deux éléments se mêlaient ainsi et non seulement dans le récit politique national qui émergeait à cette même époque, mais également dans le droit public hongrois dont les premiers fondements étaient interjetés dans des ouvrages bien complets en début du quinzième siècle. La question est de savoir si, par la suite, dans la constitution de la Nation moderne, ces éléments pouvaient se séparer ou encore un apport persiste dans le récit national hongrois ayant des conséquences en droit constitutionnel ?

La résistance s'est construite donc autour de l'idée de la défense du christianisme contre l'islam même si ce dernier, certes, très présent dans l'organisation de l'Empire ottomane, n'était pas forcément de grande influence sur le plan confessionnel dans ces territoires à la périphérie de la conquête. Pour les administrateurs de l'Empire, la perception des taxes était bien plus importante que la conversion des Hongrois à l'islam : ils manifestaient, dans leur intérêt financier, une tolérance remarquable pour les questions religieuses, qui avait pour conséquence que si la culture de l'époque était fortement marquée par l'invasion ottomane, la vie religieuse n'était pas vraiment bouleversée à l'exception de son cadre institutionnel qui se reculait à l'avancée de l'armée du Sultan.

C'est un autre évènement historique qui, par contre, inaugure une période d'influence aussi importante quoique paradoxalement, allant plus dans le sens de renforcement de l'attachement chrétien de la Hongrie. Il s'agit de la Réforme protestante qui sur un territoire hongrois où l'Église catholique institutionnelle 
recoulait justement à cette époque, trouvait une réception large. En raison de la direction des échanges intellectuels, c'est notamment la branche calviniste qui s'est rapidement installée et prenait des formes institutionnelles en Hongrie où l'Église réformée fut officiellement créée déjà cinquante années après la Réforme luthérienne. Par contre, entre chrétiens, à cette époque, la tolérance était générale, ainsi en Transylvanie, par exemple, trente ans avant l'édit de Nantes, elle fut actée par les États généraux.

C'est la reconquête des territoires hongrois sous les Habsbourg qui était à l'origine des premiers conflits religieux entre chrétiens. Adeptes de la Contre-réforme de l'Église catholique et voulant renforcer leur légitimité sur les territoires (re)conquis, les empereurs autrichiens, à la seule exception de l'empereur Joseph II, émerveillé par les philosophes des Lumières et voulant devenir un monarque éclairé, cherchaient à battre les protestants. Par cette volonté, ils ne faisaient que renforcer, à nouveau, cette foisci, parmi les protestants, le mélange entre la protection de la foi et la défense de l'indépendance nationale, comme en témoigne les mouvements d'indépendance, la défense de l'Église et de l'État se mêlait à nouveau dans une logique politique.

La Réforme protestante a également joué un rôle important dans l'émergence et le renforcement du sentiment national, la traduction de la Bible en langue hongroise tout autant que l'enseignement de plus en plus répandu ou encore les cantiques chantés en hongrois dans les temples protestants, ont contribué incontestablement au renforcement du sentiment d'appartenance nationale qui se sont mélangés, sur le plan culturel aussi, avec l'attachement confessionnel chez les protestants qui sont devenus, par la suite, des partisans encore plus hardis de l'indépendance nationale jusqu'au XIX ${ }^{\mathrm{e}}$ siècle. La question est à poser à nouveau à savoir si ce mélange entre l'existence nationale et l'appartenance religieuse dans l'héritage historique hongrois aurait des conséquences en droit constitutionnel actuel.

Car, enfin, il est à préciser qu'à l'instar des Britanniques, les Hongrois vivaient sous l'autorité d'une constitution historique, dite millénaire : la première loi de la Hongrie étant, dans tous les recueils juridiques, les instructions du roi Saint Etienne à son fils, Émeric, mort dans un accident de chasse, n’ayant jamais été couronné roi ; remplie à la fois de consignes politiques mais fortement marquée également par des idées issues du catholicisme de l'époque. Et la liste des documents écrits témoignant de l'importance du mélange entre les fondamentaux chrétiens et, pour ainsi dire, la souveraineté nationale sera très longue à citer. Il est encore plus important de mentionner que de ce fait il n'y a finalement jamais eu de rupture entre l'État et l'Église, non plus, dans ce développement constitutionnel organique.

Après avoir parcouru l'histoire de l'État hongrois dans l'objectif de démontrer comment l'Église, la confession et en général l'appartenance chrétienne des Hongrois se sont liées fortement à l'idée même de l'État hongrois, par ses fondements, dans son indépendance et sa préservation, pour pouvoir dire finalement, que le christianisme et la souveraineté nationale hongroise sont aussi étroitement liés, il est à voir, tel que nous l'avons suggéré, pour problématiser le sujet de l'étude dans ce contexte particulier, mais avec l'intention de pouvoir élargir nos conclusions à une étude plus vaste sur les rapports entre les États et les Églises ; quels sont les différents aspects sous lesquels, l'Église et la confession autour de laquelle elle se construit, peut apparaître dans la constitution de l'État et ainsi en droit constitutionnel.

Puisque, à la lecture même de ces éléments historiques, il s'avère nécessaire de bien distinguer plusieurs choses, comme nous l'avons suggéré avec l'usage le plus précis possible de différents termes. Certes, c'est la chrétienté en tant que caractère et le christianisme en tant que confession et religion à comprendre de la manière le plus large possible qui sont les choses les plus importantes, telles que ces expressions sont reprises par la Loi fondamentale. En même temps, il serait difficile de séparer nettement et clairement ces choses de l'Église et des Églises chrétiennes qui en sont porteuses. Par contre, il est à voir, notamment dans une analyse juridique, que le caractère chrétien des Hongrois d'une certaine époque, les racines chrétiennes de leur État même actuel, se présentent à des niveaux divers.

L'histoire, comme toujours, se relie au présent. Mais le poids des Églises dans la société actuelle hongroise est loin d'être le même que lors de la formation de l'État hongrois il y a plus de mille ans, ou de la Nation hongroise, il y plus de cent ans. La fréquentation des Églises, le nombre des baptêmes ou des 
mariages religieux se diminuent constamment dans une société hongroise actuelle entrant dans la modernité, voire même, dans la postmodernité. C'est dans cet écart entre la réalité sociologique et la perception de la chrétienté et ainsi des Églises qui continuent à la représenter, que la législation en la matière doit être lue et comprise ainsi grâce à une distinction entre les différents éléments. Ce ne sont pas les Églises qui en tant que telles, joueraient un rôle social et politique prépondérant, mais c'est la chrétienté, par son passé, par ses valeurs et donc dans une forme plutôt culturelle que religieuse, qui se resurgit à travers et porte fondement à ces textes juridiques, certes, en élevant, d'un certain point de vue, les Églises, d'ailleurs, même contre leur volonté, à une importance dépassant leur véritable ancrage social.

Lorsque le droit s'intéresse à la réglementation des Églises, il est ainsi à souligner qu'il s'agit d'une thématique très complexe à traduire dans les normes, conformément aux choix politiques préalables. Les Églises sont incontestablement des institutions qui peuvent entrer en tant que tel dans un rapport juridiquement défini avec l'État tout autant qu'en tant que telles, elles ont accompli des missions publiques qui sont donc à définir en droit. Mais ce n'est qu'une première approche fondée donc sur une approche institutionnelle de l'Église, indépendante et autonome de l'État mais à définir pour ces cadres et notamment pour les limites de sa construction par le droit, tout autant que le droit doit prévoir l'accomplissement des missions publiques essentielles par les Églises d'une manière juridiquement réglementée.

En dehors ou en plus de leurs formes institutionnelles, les Églises créent des communautés, soudées par leurs identités confessionnelles qui peuvent apparaître, que l'on le veuille ou non, sur le plan politique national. Le droit constitutionnel peut, nous oserions dire, doit s'intéresser à ces communautés aussi, soit pour les intégrer, en définissant les rapports avec l'État, dans la communauté nationale, soit pour les exclure, en n'acceptant que la seule communauté de la Nation. Ce choix est encore plus important, car non seulement ces communautés portent une certaine identité qui peut même corroborée, d'ailleurs, l'identité nationale, mais de plus, elles fonctionnent en tant que telles, ayant une certaine vocation sociale et accomplissement ce type de missions avec le soutien ou en concurrence de l'État.

Enfin, ces confessions sont porteuses d'idées qui ne sont pas, souvent, différentes des idées à la base de la normativité juridique, notamment constitutionnelle, il s'agit des valeurs et des intérêts qui peuvent en tant que tels apparaître donc dans le droit constitutionnel. Par son caractère général et abstrait, le droit constitutionnel s'intéresse beaucoup aux idées fondatrices d'une communauté politique qui est la Nation, et d'une normativité juridique générale, qui, par excellence, est le droit constitutionnel national, non pas neutre, mais justement imprégné de ce type d'idées, porteuses de valeur. Si le débat persiste en droit constitutionnel à savoir s'il existe des constitutions neutres, polyvalents, il nous serait impossible de démontrer que de telles constitutions peuvent longuement perdurer dans un État stable.

Une constitution n'est jamais neutre, elle se fond sur un certain nombre de permisses de base, qu'elles soient techniques et concrètes ou plus entachées de convictions philosophiques, abstraites. Au moment des transitions constitutionnelles, cette question des valeurs apparait souvent et si le travail du constituant est souvent réduit à l'adoption des normes techniques, il ne peut pas s'échapper à ces choix que l'on dirait, en absence d'un terme plus adéquat, idéologiques. Encore une fois, la nature même du droit constitutionnel exige la réflexion sur ces choix de valeurs (Trócsányi 2011,78). Ici, également, le christianisme ou d'autres confessions religieuses, peut jouer un rôle, en Europe, plus dans un aspect culturel, justement en tant qu'un ensemble de valeurs, que religieux propre.

Lorsque nous étudierons donc les rapports entre l'État et l'Église, notamment la Hongrie et les Églises en Hongrie, nous nous intéresserons à tous ces trois niveaux. L'Église institutionnelle et ses fonctions publiques apparaîtront dans notre premier chapitre consacré aux lois libérales de la fin du XIX ${ }^{\mathrm{e}}$ siècle. Une approche de l'Église en tant que communauté accomplissant des missions sociales guidera l'analyse de notre deuxième chapitre où la politique socialiste en la matière fera l'objet de notre étude. Enfin, l'Église culturelle ou plus précisément dans le cas de la Hongrie le christianisme culturel avec des conséquences bien concrètes sur les autres volets, émerge dans toute la deuxième partie de notre article, faisant l'étude du débat constitutionnel récemment émergé. 
À part ces distinctions qui nous permettra, nous l'espérons, d'apporter plus de précisions à l'analyse générale du sujet, dans une approche comparatiste aussi, même si nous nous réserverons à étudier uniquement la Hongrie, nous souhaiterons, pour terminer cette introduction, souligner ce que le titre fait également apparaître, une problématique particulière liée à la diversité des règlementations et des politiques à travers de l'histoire, c'est-à-dire dans le temps, et des Églises qui sont implantées et qui fonctionnent en Hongrie. La difficulté d'établir des règles, notamment générales et abstraites en droit constitutionnel, et un régime correspondant aux souhaits de la politique, est particulière en Hongrie, en raison de cette grande diversité.

Le constituant et le législateur hongrois ne peuvent pas oublier lors de l'adoption des normes dans ce domaine, l'histoire très compliquée des Églises en Hongrie, notamment en raison des éléments que nous exposerons dans la première partie de notre étude, et qui ont des conséquences très importantes sur la réglementation actuelle concernant les rapports entre l'État et les Églises. Encore plus, il doit tenir compte le fait que si la chrétienté reste le seul fondement mentionné, déjà parmi les Églises chrétiennes, une grande diversité existe depuis la Réforme protestante, qui demande une attention particulière lors de la définition des rapports avec chacune de ses Églises, et pendant que le judaïsme est aussi historiquement présent, avec la mondialisation, de nouvelles confessions s'installent en Hongrie.

Il n'est pas possible et, d'ailleurs, dans nos convictions, il n'est pas opportun, non plus, de vouloir imposer une approche qui est, peut-être, adéquate à un contexte différent où les Églises n'ont pas forcément connu autant de troubles et les mêmes bouleversements de l'histoire, dans la définition des rapports entre l'État hongrois et les Églises en Hongrie. De même, il est essentiel, si ce n'est que dans un souci de traitement équitable et égalitaire, de tenir compte au fait que la Hongrie était toujours un pays d'une communauté nationale aussi multi-ethnique que multi-religieuse, certes, avec une tradition judéo-chrétienne à l'image des autres États de l'Europe mais où aucune Église n'a obtenu un rôle prédominant. Au travers de l'analyse, il est à voir si cette diversité peut être à l'origine d'un vivre-ensemble paisible.

\section{La diversité des régimes juridiques dans l'histoire de la Hongrie}

Si l'identité hongroise est fortement marquée, dans un contexte de l'Europe centrale, où les invasions par et les conflits entre des puissances diverses étaient très présentes, par l'idée de l'indépendance et de la résistance nationale, et justement la chrétienté comme élément composant de cette identité, est considérée comme un caractère permettant la consolidation et la préservation de l'État hongrois; en droit public, et notamment en droit constitutionnel, les rapports, même dans cette logique de mélange entre la défense et la préservation de l'État et des Églises chrétiennes, faisaient l'objet d'une définition propre. Et lors de la réglementation de ces rapports, la Hongrie a pu adopter des règles diverses en suivant des approches politiques différentes au cours de son histoire.

Par contre, même dans cette logique de défense ou, d'ailleurs, de résistance, le législateur hongrois, tout autant que l'État hongrois dont il adoptait les normes, ne pouvait pas s'échapper au contexte historique. Les invasions et les conflits ne s'y sont pas apparus uniquement dans l'exercice concret et dans des rapports de pouvoir, avec l'arrivée des armées, mais ils se faisaient également par de moyens plus doux qui étaient souvent aussi, voire même, plus tranchants : par des tendances idéologiques et donc l'arrivée des idées diverses. Il est à noter que déjà le christianisme s'est installé dans le bassin des Carpates par l'influence occidentale. Or cette première influence, même dans une Hongrie qui a vécu son histoire à son rythme, était suivie par d'autres, issues d'un développement qui donc n'était pas forcément propre à la Hongrie.

Ce sont ces « invasions et conflits » des idées et entre les idéologies qui ont souvent contribué à l'adoption des régimes juridiques très divers dans notre domaine d'étude. La diversité dans le temps que cette première partie de notre analyse vise à exposer, est incontestablement due aussi à ces phénomènes 
d'influence. Il est intéressant de voir comment dans un contexte bien particulier, celui de la Hongrie d'une telle ou telle époque, ces influences pouvaient apparaître et faire émerger des politiques et des régimes juridiques particuliers aux effets éventuellement très éloignés des attentes originaires. Sans entrer dans une analyse qui devrait être plus poussée, dans la réception des idéologies dans les règlementations constitutionnelles, nous souhaiterons simplement souligner l'intérêt d'une telle problématique aussi.

Lorsque ces idées nouvelles peuvent s'intégrer dans une évolution propre au contexte hongrois, les résultats escomptés par le législateur, bien entendu, à condition que le travail de l'adoption des normes soit également bien mené, pouvaient être atteints, certes, il fallait également que ce législateur ait fait preuve d'une certaine modération même s'il menait des débats virulents, notamment vu le caractère extrêmement délicat, en raison de sa relation très étroite avec l'identité nationale, du sujet. Dans le cas opposé, même si cette certaine modération était présente dans l'action des politiques, et des résultats pouvaient, certes, être toujours atteints, les choix politiques pouvaient créer des effets contre-productifs ou encore des ruptures qui seraient, par la suite, à effacer ou à compenser d'une manière ou d'une autre.

Dans le cas des lois libérales faisant l'objet d'étude dans notre premier chapitre, c'est la tendance, bien entendue, libérale de la fin du $\mathrm{XIX}^{\mathrm{e}}$ siècle qui est l'idéologie dominante à l'origine de l'adoption d'un nouveau cadre constitutionnel et légal dans les rapports entre l'État hongrois et les Églises en Hongrie. Elle privilégie une approche que nous avons qualifiée institutionnelle. Concernant la politique socialiste, c'est bien évidemment le socialisme d'État qui sera l'arrière-fond idéologique très visible. Ici, nous parlons volontairement de la politique, car les règles sont plutôt administratives, et l'action politique prédomine, mais la rupture est bien forte : dans une approche communautaire et sociale, les Églises devront subir les conséquences d'une volonté politique fortement idéologisée.

Le choix de ces deux périodes pour une étude plus approfondie est non seulement motivé par leur caractère marquant l'histoire dans les rapports entre l'État hongrois et les Églises en Hongrie ; mais aussi, parce que, comme nous l'avons introduit ci-dessus, même si les deux actions sont motivées par des choix idéologiques issus des influences extérieures, leurs niveaux d'intégration dans le contexte hongrois, malgré, encore une fois, d'une certaine modération des acteurs, étaient très différents. Or, dans notre hypothèse, cela ne dépendait pas vraiment du bien-fondé de l'idéologie qu'il suivait, mais justement de cette capacité d'intégration qu'elles ne reflétaient. Enfin, par ce choix, nous souhaitons également exposer deux approches sur deux plans différents : l'une institutionnelle, l'autre communautaire.

\section{I.1. Les lois libérales de 1894 et de 1895}

L'Assemblée nationale hongroise avec une majorité des conservateurs libéraux a adopté une série de lois constitutionnelles d'importance incontestable à la veille du nouveau siècle. Réunie suite au Compromis de 1868 , forte de son prestige institutionnel qu'allait refléter si bien le plus grand bâtiment parlementaire de l'Europe continentale, pendant longtemps, concurrencé à ce titre uniquement par le Westminster britannique dans le monde ; l'Assemblée a mené des débats particulièrement virulents à ce sujet. Si les idées libérales de l'Europe occidentale ont fait la conquête de l'élite politique et de l'opinion publique hongroise, non sans rapport avec l'identité nationale fortement marquée par le christianisme, les conservateurs hongrois avaient du mal à accepter la proposition gouvernementale.

Non seulement les hésitations, notamment dans certains départements, dans l'exécution des lois témoignent de ce débat particulièrement vif (Kárbin, 2008, 25), mais le fait que le gouvernement, ayant perdu sa majorité à l'Assemblée nationale, a dû démissionner en raison de l'adoption des lois controversées, est le signe incontestable de la délicatesse du sujet législatif. La séparation de l'État et de l'Église très à l'air du temps, pourtant, n'étaient pas catégorique en Hongrie, et même si les Églises, notamment l'Église catholique romaine, y voyaient une remise en cause de leur autorité (ibid., 27.), il est à noter que les lois hongroises ne concernaient que les fonctions publiques de l'Église, pour ainsi dire, institutionnelle. Il était en question la conclusion des mariages, les procédures devant l'état civil et le choix de la religion des enfants. 
Ainsi que nous l'avons remarqué, il est constant que c'est la tendance libérale de l'Europe occidentale de l'époque qui était le fondement, au niveau des idées politiques, de l'adoption des dispositions législatives ayant valeur constitutionnelle même, justement car s'agissant des rapports entre l'État et les Églises. Dans cette idéologie moderne, l'État devait prendre ses distances des religions et des idées religieuses, mais surtout il devait se distinguer nettement de l'Église institutionnelle en assumant, seul, les fonctions publiques qui historiquement et traditionnellement ont été exécutées par les Églises. Régulant les rapports, notamment en droit de famille, ces dernières avaient la mainmise sur les questions dont disposeraient les lois constitutionnelles désormais.

Dans une première approche, l'on pourrait s'étonner de la virulence des débats, les lois ne prévoyant que le mariage civil et l'état justement civil et non plus ecclésiastique ainsi qu'une régulation législative sur l'affiliation confessionnelle des enfants, tout à fait conforme aux coutumes que les Églises ont également appliquées à l'époque. Et pourtant l'on parle, à juste titre, des lois constitutionnelles inaugurant en Hongrie la séparation de l'État et les Églises (ibid., 23). La procédure législative, d'ailleurs, après l'entrée en fonction du prochain gouvernement, ayant pu obtenir la confiance de l'Assemblée nationale, a été couronnée par la loi sur la liberté religieuse, très importante également en raison de l'émancipation de la confession juive, jusqu'à cette époque plutôt tolérée qu'intégrée par les autorités.

D'abord, il est à souligner que c'est dans la partie la plus vive des prérogatives des Églises que ces lois apportent des changements en ôtant justement les Églises institutionnelles de ces fonctions publiques. Le rapport entre les familles et l'État seront ainsi constitués directement, puisque c'est ce dernier qui est compétent pour la question du mariage. Or, même si aujourd'hui, la notion même de la famille connaît un bouleversement qui est considéré souvent radical, il est constant que toute société est composée de personnes mais également de familles, qui sont les communautés les plus petites et en même temps les plus évidentes du vivre-ensemble collectif. Or, la constitution de ce noyau revenait à l'Église qui était ainsi symboliquement aussi régulatrice des rapports les plus intimes.

C'est cette fonction publique des Églises qui leur serait ainsi prise par l'État qui serait la seule autorité à réguler et à constituer même la famille, encore une fois, communauté à l'origine de toute la construction sociale. Et nous avons vu par l'exposé rapide de la réception de la réforme au sein de la société hongroise que l'enjeu symbolique était largement perçu. C'est ce qui ressort également des débats parlementaires où nombreux étaient les parlementaires conservateurs qui ont levé la voix contre la réforme en accusant l'État d'une ingérence particulièrement blessante dans les Églises institutionnelles mais également de la destruction d'un statu quo largement accepté et considéré comme une valeur prestigieuse par ces tendances conservatrices (ibid., 22).

La modération donc finalement n'a pas permis d'atténuer ces débats. Encore une fois, pourtant, la législation étatique n'a pas touché aux Églises dans leurs constructions religieuses, ce n'est que pour ces rapports en droit de famille qu'elle les concernait. De plus, après leur avoir retiré ces prérogatives, certes, plus qu'administratives, car hautement symboliques, l'Assemblée nationale n'a fait que reconnaître la liberté religieuse et d'ailleurs, elle a invité les Églises qui ont répondu, toutes, volontairement à cette invitation, de reformuler leurs statuts propres, adoptés dans le cadre de leur autonomie institutionnelle. Il est à noter et à souligner que le caractère particulier des Églises a toujours été accepté, voire même renforcé par ces lois constitutionnelles.

Ces lois n'ont nullement changé ainsi la structure institutionnelle des Églises, loin de là, elles ont réaffirmé et ainsi ont reconnu leurs constructions particulières. C'est à partir de cette époque-là que la terminologie constitutionnelle hongroise connaît l'expression des Églises traditionnelles, traduites en français dans les jurisprudences internationales contemporaines, en tant qu'Églises incorporées - le mot original a plus le sens « intégrée ». Sans entrer dans une polémique que nous jugerions volontairement inutile, concernant les termes en usage dans la matière, nous remarquons juste que s'il s'agit d'une reconnaissance particulière des Églises qui sont historiquement présentes en Hongrie, nous avons rappelé à ce titre que la Hongrie est un pays traditionnellement multi-religieux où plusieurs Églises s'intègrent à la société hongroise. 
L'État ne fait, par-là, que reconnaître une réalité historique, d'ailleurs, d'une manière très ouverte, pour ne pas dire, progressiste, en élevant au statut de ces Églises, la communauté juive de la Hongrie de l'époque par une émancipation historique. Et lorsque le législateur définit ces Églises en tant que telles, c'est pour, tout en les reconnaissant, leur prévoir le domaine particulier confessionnel tout en les excluant, comme nous venons de le démontrer, de l'exécution des fonctions publiques. Dans la logique du législateur hongrois, il est donc à faire la distinction entre l'acceptation très large de l'Église en tant qu'institution particulière confessionnelle, les familles et leur organisation et la pratique confessionnelle des personnes.

Cette série législative se compose très précisément des lois $n^{\circ} \mathrm{XXXI}$ sur le droit du mariage, $\mathrm{n}^{\circ} \mathrm{XXXII}$ sur la confession des enfants, $\mathrm{n}^{\circ}$ XXXIII sur l'état civil public, toutes les trois de l'an 1894 et de la loi $n^{\circ}$ XLIII sur la liberté religieuse, cette dernière étant, même dans une comparaison à l'échelle européenne, la plus connue et reconnue. Sans entrer dans les détails des dispositions de ces quatre lois dont l'importance, dans notre opinion, a déjà été bien démontrée ci-dessus dans l'analyse générale de leur apport et de leur particularité, il est, tout de même, intéressant d'en citer quelques articles plus pour faire apparaître quelques particularités que pour motiver ou enrichir d'exemples notre argumentaire précédent.

Ainsi la loi, d'ailleurs, la plus débattue à l'époque, sur le mariage civil, prévoit simplement qu'un mariage valide ne peut être déclaré que devant l'officier de l'état civil. Tout en établissant un nouveau système de la constitution des mariages où tous les éléments sont à définir à savoir devant qui exactement le mariage sera constitué et quelle est la procédure de cette constitution de l'union de vie. Enfin, dans une logique où l'on voulait exclure que les Églises reprennent la main sur la procédure, des sanctions pénales ont été introduites. Le mariage devrait donc se constituer devant l'officier de l'état civil. La procédure de sa constitution est publique, c'est la déclaration unanime de deux personnes de leur intention libre de se marier à la suite de laquelle l'officier pourrait constituer le mariage.

Pour empêcher les représentants des Églises de revenir en arrière, la loi prévoit donc en tant que sanctions des amendes pécuniaires lourdes ainsi qu'en cas de récidivisme, des peines de prison pour les pasteurs ou d'autres personnes « compétentes pour exécuter des services ecclésiastiques » qui procéderaient à la conclusion des mariages. Le mariage ecclésiastique pourra, bien entendu, toujours se faire mais uniquement dans le cadre séparé de l'Église et surtout pour les personnes qui ont la preuve et qui ont pu justifier légalement que leur union matrimoniale a déjà été constituée devant l'officier de l'état civil. Cette solution légale est, d'ailleurs, toujours en vigueur en Hongrie où le mariage devant l'Église ne peut se faire qu'après la célébration du mariage civil.

Le législateur devait aussi comprendre qu'en raison de cette réforme sur le mariage, tout le système de l'état civil public était à créer. C'est dans cet objectif, en raison de l'adoption de cette première législation que la deuxième loi mentionnée dans notre analyse, a dû être adoptée. Les critiques, d'ailleurs, étaient très nombreuses justement à ce titre, car la constitution de l'état civil public ne nécessitait pas uniquement des mesures administratives de la part de l'État mais des sommes d'argent importantes devaient également être engagées pour son financement (ibid., 23). Un argument fort de ceux qui s’y opposaient, venait donc des coûts qu'ils ont jugés exorbitants et, bien entendu, inutiles de la création et du financement de l'état civil public.

La loi est sans équivoque : elle mentionne que des pasteurs, des rabbins ou d'autres personnes « compétentes d'exécuter des services ecclésiastiques » ne pourraient pas devenir des officiers de l'état civil. Les procédures devant l'état civil sont obligatoires et gratuites, les Églises devront remettre leurs registres à l'officier de l'état civil qui sera ainsi la seule autorité compétente pour tenir ces annales. Cela n'empêche pas les Églises d'avoir leurs recueils propres qui d'ailleurs, continuaient à être utilisés même dans les procédures administratives et juridictionnelles comme faisant preuves. Mais l'état civil public se tiendra, d'une manière continue à partir de ce moment avec toutes les conséquences administratives et financières, dans des procédures bien définies.

Concernant l'affiliation religieuse des enfants comme nous l'avons déjà mentionné, ce sont les coutumes déjà en usage à l'époque qui seront élevées au rang de la loi. La question ne se pose que dans les mariages mixtes où les parents appartiennent à deux Églises différentes. Dans l'État hongrois multi-religieux, ce cas 
de figure était relativement répandu. D'abord, les parents peuvent décider au moment de la conclusion du mariage « une fois pour toutes » dans quelles religions leurs enfants communs seront élevés. En absence, d'un tel accord, les enfants reprendront la confession des parents de leur sexe : les filles celle de la mère, les garçons celle du père. Enfin, pour les enfants naturels, c'est la confession de la mère qui sera attribuée.

Il est à relever que là aussi, la loi parle des Églises traditionnelles, intégrées ou des Églises légalement reconnues. Encore une fois, il ne s'agit nullement d'une disposition légale discriminatoire, comme nous allons voir la liberté religieuse était constitutionnellement reconnues à cette même époque. La loi ne fait que constater une situation de fait où justement, il existe des Églises traditionnelles, intégrées dans la société hongroise et des Églises que la loi reconnaît. Ces Églises sont à considérer comme fonctionnant aux yeux de la loi en Hongrie même dans un contexte de liberté religieuse où des Églises, satisfaisant un certain nombre de conditions prévues par la loi, peuvent se constituer librement, elles bénéficient du constat de leur existence par le droit en vigueur.

Enfin, la loi sur la liberté religieuse marque une avancée constitutionnelle importante dans le droit hongrois. Elle dispose clairement : «Toute personne peut confesser et suivre n'importe quelle foi ou religion qu'elle peut exprimer et pratiquer dans les limites des lois du pays et des attentes de la moralité publique »; de même, « Personne ne peut être empêchée dans l'exécution des services ecclésiastiques qui ne seraient contraires à la loi ou aux attentes de la moralité publique et ne peut être obligé d'exécuter des actes religieux contraire à sa foi ». De plus, la loi dispose également que « la capacité d'exercer des droits civiques et politiques est totalement indépendantes de la confession de la personne », tout autant que «la foi de la personne ne peut pas l'exonérer de l'exécution d'une obligation légale ».

En Hongrie, il est ainsi introduit une liberté religieuse très générale. Permettant, avec quelques exceptions, notamment si la confession était contre la préservation de l'État et de la Nation ou si sa dénomination et ses services portaient atteints aux droits d'autres Églises, la constitution libre des Églises avec quelques conditions minimales. Et en même temps, la loi prévoit que si, comme nous avons vu, l'État et les Églises ne sont pas nettement séparés, les droits civiques et politiques ainsi que les obligations légales au bénéfice et à la charge des personnes sont définis d'une manière clairement indépendante de la confession de la personne ainsi que de son appartenance ou non-appartenance à telle ou telle Église. La liberté religieuse est ainsi également moyen de marquer une séparation entre le public et le confessionnel.

Ainsi que nous l'avons remarqué, l'approche est purement institutionnelle à cette époque. Les Églises sont reconnues par l'État qui leur assure même un statut privilégié. Par contre, les fonctions publiques sont reprises par l'État. Et même, l'État prend ses distances aux Églises, en leur permettant de fonctionner librement mais, dans cette approche institutionnelle, c'est la personne du fidèle qui apparaît à titre individuel et non pas d'une manière collective ; au niveau des personnes en faisant distinction entre, pour ainsi dire, les droits et des obligations publics et les engagements confessionnels. Cette approche fondée sur une tendance libérale, intégrée dans la législation hongroise avec beaucoup de modérations, était finalement très largement acceptée et par les Églises et par la société hongroise de l'époque. Ces lois sont aujourd'hui interprétées comme les résultats donc d'un compromis bien équilibré.

\section{I.2. La politique socialiste}

C'est justement ce compromis équilibré, voire même, le sens du compromis qui a manqué aux dirigeants du Parti hongrois socialiste du travail, entre autres, dans la matière de la politique menée vis-à-vis des Églises. Arrivés au pouvoir, à la suite de l'occupation soviétique du pays, les socialistes se sont intéressés à la question des Églises. Conformément aux méthodes politiques du Parti, ils n'ont pas autant utilisé le droit comme moyen de leur action dans l'exercice du pouvoir public mais ils menaient une politique à travers des actions précises. Ces actions, certes, avec des approches très différentes, étaient tout au long du socialisme et du règne du Parti, menées contre les Églises, considérées comme forces réactionnaires qui devraient être affaiblies et finalement, anéanties - mais avec souplesse.

Dans notre étude, par ce chapitre consacré à la politique socialiste des Églises, nous nous intéresserons 
plus particulièrement à la période après la Révolution de 1956 car elle a marqué un tournant important dans la politique socialiste. Si la première période était caractérisée par une lutte acharnée et une répression directe des Églises en tant qu'institutions, des pasteurs en tant que leurs représentants et enfin des fidèles, membres de leurs communautés, après la Révolution, une politique plus complexe, pour ainsi dire, plus subtile a été mise en place (Rajki, 2003, 37). Elle mérite d'être étudiée, toujours dans cette même logique, cherchant des éléments qui permettront de mieux comprendre l'état actuel des choses, mais également pouvant faire l'objet d'une réflexion comparatiste sur la question.

Il est à noter, tel que nous l'avons déjà remarqué, que la politique socialiste s'intéressait aux Églises, non pas en tant qu'institutions qui, à travers leurs fonctions, pouvaient concurrencer le pouvoir public, mais surtout en tant que communautés. Cette approche communautaire, combinée aux méthodes socialistes, a donné lieu à une politique qui paradoxalement, ne cherchait pas à couper tous les liens entre l'État socialiste et les Églises établies, mais au contraire, voulait constituer des rapports concrets et nuancés dans l'objectif de maintenir le Parti au pouvoir mais également dans la logique que l'idéologie socialiste imposait. Elle servait le renforcement de la communauté populaire socialiste qui voyait dans ces communautés, de la concurrence mais aussi un moyen de sa propre action.

L'approche idéologique socialiste est reçue des Soviétiques qui occupaient les territoires hongrois, un élément à ne pas oublier, par la force militaire. La Révolution de 1956 ne pouvait être battue que par l'arrivée des chars russes dans la capitale et dans les villes de la province hongroise. Si l'idéologie a été largement reçue et a servi comme fondement à toutes les politiques menées par le Parti au pouvoir, il est à souligner que là aussi, dans le contexte hongrois, des modérations, notamment dans la période faisant l'objet de notre étude, ainsi que des contradictions au sein même du Parti, composé de différentes tendances, se manifestaient et la politique menée était l'objet d'un débat permanent, notamment entre l'extrême- gauche et les plus modérés du Parti.

Il est, néanmoins, constant que dans l'idéologie communiste, les Églises et les communautés confessionnelles sont considérées comme des « ennemis du peuple », « des forces réactionnaires » à combattre dans une logique de « lutte des classes » (ibid., 38). Mais pendant que pour la gauche plus radicale du Parti, il s'agissait de constructions obsolètes qui devront être détruites par tous les moyens dont les socialistes disposaient, pour d'autres, elles étaient des communautés qui, d'une part, de toute manière, allaient disparaître par le progrès social, d'autre part, en attendant, pouvaient servir les objectifs du Parti. Si la première tendance était majoritaire avant 1956, après la Révolution, la deuxième tendance se renforçait et a pu justement influencer d'une manière très efficace, la politique du Parti (ibid. 37).

Les acteurs qui ont joué le rôle essentiel pour mener la politique socialiste envers les Églises, peuvent être bien différenciés. Si le Parti avec ses différentes instances, notamment par son Bureau central mais aussi par son Département d'agitation et de propagande, responsables pour les affaires des Églises, étaient l'organe de décision, notamment dans notre période, il faisait plutôt intervenir les autorités publiques étatiques. Le Parti, qui déclarait ouvertement la guerre idéologique aux Églises, trouvait important de montrer qu'il ne menait justement que la guerre des idées, pour toute autre question les instances nationales compétentes devaient intervenir, parmi eux, le Ministère de l'intérieur et puis, d'une manière de plus en plus importante, le Bureau national des Églises (ibid.).

Concernant les moyens d'intervention, il est à noter qu'ils étaient, comme nous l'avons déjà mentionné, plutôt politiques, au pire, administratifs. Si dans la période précédent à la Révolution, c'est par l'intervention policière et une répression juridictionnelle, notamment pénale, que les Églises, les pasteurs et les fidèles ont été menacés, dans cette deuxième période du socialisme d'État, ce sont les mesures politiques et administratives, et surtout des actions précises de la part des autorités et notamment du Bureau national de plus en plus puissant qu'encore une fois, par lesquels des rapports nuancés étaient établis et une politique envers des Églises était mené par l'État socialiste. Ce dernier, d'ailleurs, ne se déclarait pas contre les Églises : il protégeait même la liberté religieuse.

Néanmoins, dans l'idéologie communiste, c'est justement l'apparence publique de la liberté religieuse qui est à éviter et pas tellement la pratique des services, nous pouvons mentionner que la célébration des 
baptêmes, des saintes cènes, des confirmations ne faisait plus l'objet de répression officielle déjà à cette deuxième période. Mais le fait que les Églises construisent des communautés qui, par leur influence, peuvent concurrencer le Parti et les organisations que celui-ci a mis en place, notamment le Front national patriotique ou l'Alliance de jeunes communistes, continuait à déranger. Ce sont les actions communautaires que ce soit pour des objectifs de solidarité ou de vie en communauté tout simplement qui étaient donc considérées comme menaçantes et contre lesquelles les autorités étatiques cherchaient à agir.

Les responsables du Parti et les autorités qu'ils dirigeaient, ont compris rapidement que les Églises ne sont pas uniquement des institutions religieuses mais elles s'intéressent, d'une manière générale et traditionnelle, à l'organisation de la vie de toute une communauté. Elles proposaient des actions et des activités que les socialistes ont jugé dangereuses non seulement en raison de la lutte contre les confessions considérées comme réactionnaires dans leurs idées, mais aussi parce que le Parti voulait détenir le monopole de ce type d'actions et d'activités tout simplement pour être le seul acteur qui influence ainsi, également sur le plan idéologique, la vie des citoyens. Ils ont donc mis en place leur politique envers des Églises pour remplacer ou plus tard plutôt pour influencer les communautés de ces dernières.

Certes, les moyens de répression y jouaient toujours un rôle important. C'est là qu'aucun élément de compromis ne pouvait être autorisé. Les représentants dits réactionnaires des Églises ont été soit condamnés soit bouleversés par tous les moyens dans leurs vies professionnelles et privées. Dans de nombreux postes, les personnes qui auraient pratiqué telle ou telle confession religieuse, ne pouvaient pas être admises ou pire encore, les enfants des personnes ouvertement pratiquantes n'étaient pas admis à l'université ou dans des formations destinées à de futures élites. Mais ce n'était qu'un élément de la lutte contre les Églises avec lesquelles, encore une fois, des rapports nuancés ont été constitués pour qu'elles servent les intérêts des socialistes.

De cette logique découle le fait que les activités purement religieuses, notamment dans cette deuxième période du socialisme d'État en Hongrie, n'étaient pas donc directement concernées par les actions menées dans le cadre de la politique socialiste. Il ne s'agit pas uniquement des activités cultuelles mais aussi de la formation des pasteurs ou encore de l'édition ou de diffusion des livres et d'autres publication à contenu purement confessionnel (ibid., 40). Par contre, toute action ou activité qui pouvait avoir un rapport même indirect avec la vie en communauté, était interdite ou au moins contrôlée. Ainsi, par exemple, le contenu des journaux édités par les Églises faisait l'objet de contrôle sérieux mais au lieu de les interdire, les socialistes y trouvaient même un moyen à leur propre propagande.

La particularité de la politique socialiste envers les Églises, notamment en Hongrie, était justement d'établir des liens forts et quotidiens entre les Églises et les autorités nationales afin que ces dernières puissent les utiliser à leurs fins. Car, si idéologiquement, la confession était considérée comme nocive, la capacité des Églises de constituer et de consolider des communautés intéressait beaucoup les responsables du Parti. Les socialistes voulaient ainsi s'infiltrer dans les Églises institutionnelles afin d'utiliser ces capacités pour leurs propres fins, notamment idéologiques. L'exemple le plus connu de cette action est le Mouvement de paix qui officiellement, était initié par les Églises mêmes, bien évidemment, à l'encouragement du Parti et qui permettait de dénoncer les crimes impérialistes (Székely, 2008, 3).

Cette infiltration se faisait, d'une part, dans la direction même des Églises institutionnelles où l'État a détenu un droit de veto, y compris dans l'Église catholique romaine grâce au fameux accord partiel que la Hongrie a pu obtenir du Vatican dans les années 60. Ainsi tous les dirigeants des Églises étaient des personnes jugées ouvertes et utiles pour la coopération avec l'État. De plus, grâce à ces personnes, les autorités nationales pouvaient mettre sur le plan interne tous les conflits qu'elles avaient avec des pasteurs considérés réactionnaires qui ont dû subir des sanctions de discipline à l'intérieur même de leurs Églises. D'autre part, l'infiltration se réalisait justement au niveau des pasteurs qui devaient être au moins neutres, au mieux, des pasteurs dits de paix, engagés pour le régime socialiste.

Au lieu de les empêcher, ainsi l'État soutenait même les activités des Églises. Il subventionnait, par exemple, l'achat des motos et plus tard, des voitures de fonction afin que ces pasteurs partisans du régime puissent faire un travail de propagande parmi leurs fidèles au bénéfice des socialistes (Rajki, 2003, 42). 
Les autorités étatiques ne géraient pas seulement un relationnel quotidien sur le terrain avec les responsables des Églises, mais de plus, elles organisaient des formations pour ces derniers, et les encourageaient même à partager les connaissances politiques nouvellement acquises dans leurs communautés respectives. Si l'État luttait contre les idées, il voyait dans les communautés un moyen de diffuser sa propagande : il n'est pas un hasard qu'au Bureau national des personnes bien qualifiées travaillaient.

Certes, les confessions religieuses ont été toujours présentées comme arriérées, réactionnaires dans les médias ou dans les programmes officiels d'enseignement et de formation. Mais l'État socialiste qui luttait donc contre la religion, ne voulaient pas supprimer les communautés religieuses. D'ailleurs, notamment à partir des années 70, même le Bureau national des Églises qui craignait que son importance ne diminue si les églises se vidaient, apportait des arguments pour maintenir en bon état ces communautés pouvant, disait-il, servir le régime socialiste en place et non seulement sur le plan national interne mais également dans un contexte international où ces pasteurs, dans leurs Églises respectives, devaient défendre la Hongrie et les politiques menées par les dirigeants socialistes.

Et dans le bloc socialiste, la Hongrie était présentée comme un bon exemple à suivre dans la matière avant même la libéralisation générale à partir du milieu des années 80 (ibid., 46.). Cette politique socialiste hongroise, encore une fois, dans son approche centrée sur les communautés que les Églises pouvaient créer, en infiltrant les Églises et en établissant des liens forts et opérationnels avec eux, même dans la logique de l'idéologie socialiste qui est ouvertement contre les Églises, a pu prouver comment les Églises pouvaient servir les objectifs socialistes. Ces communautés confessionnelles où les fidèles, certes, se voyaient attaqués dans leurs convictions religieuses, dirigées par des pasteurs et des responsables ecclésiastiques partisans du socialisme, pouvaient être des lieux de la propagande socialiste.

À partir du moment où, d'ailleurs également grâce à la reprise en main de ces communautés par des pasteurs engagés plus contre que pour le socialisme, leurs activités pouvaient repartir sur le terrain traditionnel de la défense et de la promotion de la foi confessionnelle, l'on organisait notamment des excursions, des concerts, 1 'on créait des groupes de jeunes. Déjà dans les années 80 , la pratique confessionnelle en communauté représentait à nouveau une menace et servait même du cadre nouveau dans la lutte de plus en plus ouverte contre le régime socialiste car l'élément confessionnel ne pouvait pas être clairement distingué du débat public ; dans ce sens non plus, le Parti devait voir donc son jeu inversé qui contribuait incontestablement au changement de régime.

Il est à noter, à travers de l'étude présente de la politique socialiste vis-à-vis des Églises que si dans une idéologie libérale, par une approche institutionnelle, les fonctions publiques peuvent être prises par l'État aux Églises et que toujours dans une telle logique libérale, la liberté religieuse pouvait être assurée, en faisant une séparation, au niveau des personnes entre les droits et les obligations, pour ainsi dire, publics, et les engagements confessionnels, l'approche communautaire des socialistes démontre bien que les Églises sont plus que de simples institutions puisqu'elles créent et consolident des communautés importantes dans l'objectif, certes, de la vie confessionnelle qui en tant que telle peut être distinguée de la sphère publique, mais également avec un certain intérêt pour la vie plus générale de leurs communautés.

Le choix des socialistes était, dans cette deuxième période du socialisme d'État en Hongrie, fait pour utiliser cette capacité des Églises, et pour cela, de tisser des liens étroits avec elles. Il est intéressant de voir comment malgré leurs oppositions idéologiques, cette collaboration pouvait se montrer utile finalement dans le contrôle des idées au sein d'une communauté. En même temps, les Églises ont dû payer un prix lourd pour cette politique de collaboration, car leurs communautés se voyaient finalement affaiblies lourdement à cette période. Pour certains, la collaboration a eu un effet plus dévastateur sur les Églises que la nationalisation de leurs moyens de fonctionnement au cours des années 50. Quoiqu'il en soit, l'approche communautaire reste intéressante aux yeux des politiques.

Enfin, dans une logique de diversité, par une présentation, certes, très générale mais suffisamment précise, nous espérons en tirer des constats utiles; de deux modèles dans la gestion des rapports entre l'État et les Églises, nous avons également pu témoigner de l'importance de ces dernières, conformément à ce qui a 
déjà été décrit dans notre introduction. Même dans une approche institutionnelle, cherchant en suivant la logique libérale, les Églises ont été reconnues en tant qu'entité spéciale : intégrée à la société nationale, et encore plus curieux, dans une idéologie condamnant les Églises en tant que forces réactionnaires, leur rôle a été redécouvert et elles étaient maintenues en tant que communautés particulières dans la promotion des idées et la consolidation des communautés. De cette lecture historique ressort donc également ce caractère spécifique, particulier des Églises en Hongrie.

\section{La diversité des Églises en Hongrie}

En début de la deuxième partie de notre analyse qui s'annonce purement juridique et porte sur l'actualité, nous soulignons l'importance des constats précédents. Lorsque nous étudierons les réglementations juridiques, constitutionnelles et législatives entrées en vigueur depuis le changement de régime, tel que le constituant et le législateur les ont adoptées, nous devrons nous mettre dans le contexte hongrois. D'abord, les Églises ont subi des répressions et même, par le jeu machiavélique du Parti au pouvoir pendant quarante ans d'occupation soviétique, une destruction massive de leurs communautés sans parler de la nationalisation de leurs biens. Deuxièmement, le retour à la constitutionnalité au moment du regain de l'indépendance, était, certes plus lentement que prévu, également un retour aux traditions constitutionnelles.

Il est constant tel que nous l'avons rappelé à plusieurs reprises que l'État hongrois et les Églises en Hongrie vivaient historiquement dans une interdépendance forte, l'identité chrétienne étant un élément constituant de l'identité nationale, la chrétienté que représentent les Églises, est entrée dans un rapport constant avec l'indépendance et ainsi avec la souveraineté nationale, tel que nous avons posé la question, il est à voir quel est l'apport de cette interdépendance dans le droit constitutionnel moderne et contemporain. Nous répétons également que pour mener à bien notre étude, il est important de faire la distinction entre les Églises en tant qu'institutions particulières confessionnelles, en tant que communautés ayant des missions sociales et en tant que porteuses de valeurs, cette dernière définition gagnant de plus en plus d'importances de nos jours.

\section{II.1. La politique contemporaine}

Au moment du changement de régime, la Hongrie n'a pas adopté une constitution toute nouvelle. La transition dite démocratique sur le plan constitutionnel est intervenue par une révision générale de la constitution en vigueur pendant la période du socialisme qui était, d'ailleurs, la première constitution écrite de la Hongrie qui connaissait, rappelons-le, avant un régime de constitution historique. Lors de cette révision, le libellé constitutionnel a été complètement reformulé mais la numérotation est restée inchangée. Les négociations de l'époque qui ont amené à cette révision constitutionnelle, ont donné comme résultat, une solution, pour ainsi dire, minimaliste : des normes techniques ont été adoptées conformément à ce que nous pourrions appeler les exigences libérales de la constitutionnalité moderne.

Cette révision était très importante, car elle a permis à la Hongrie de se constituer comme une démocratie libérale avec le respect des droits fondamentaux et l'organisation des élections libres. En même temps, ce nouveau libellé, considéré, d'ailleurs, par ses auteurs comme temporaire déjà à l'époque de son adoption, n'avait pas vraiment de caractère hongrois. Il ne reflétait que l'état de l'art constitutionnel libéral de l'époque ce qui était, on le répète, une avancée importante pour une Hongrie auparavant socialiste mais insuffisante dans les yeux de nombreux qui voulaient également retrouver dans les normes constitutionnelles hongroises, les éléments propres à la Hongrie, ayant un développement constitutionnel millénaire avec des particularités bien identifiables.

Concernant notre sujet, le rapport entre l'État et les Églises, cette révision constitutionnelle donc ne prévoyait que ce qui était acquis dans l'Europe occidentale déjà à l'époque, c'est-à-dire la garantie de la liberté religieuse telle qu'elle ressort également de la jurisprudence internationale, notamment de celle de 
la Cour européenne des droits de l'Homme. Sur la base de cette disposition constitutionnelle, une loi très libérale a été adoptée par l'Assemblée nationale démocratiquement élue, en 1990 qui disposait avec des conditions très minimales sur la constitution des Églises. Une centaine de personnes réunies autour des dogmes qu'ils considéraient religieux et qui n'allaient pas à l'encontre de l'ordre public, par une simple demande, pouvait enregistrer une Église devant les tribunaux départementaux. (La loi nº 4 de l'an 1990)

Si les Églises traditionnelles pouvaient ainsi se reconstituer juridiquement, cette législation a ouvert la voie libre à la création de toute sorte d'Églises nouvelles. Et lorsqu'après la conclusion du traité avec le Vatican en 1996, une législation propre a été adoptée sur les subventions étatiques et les exonérations, notamment en matière de la fiscalité, donnant le même traitement qui a été négocié par l'Église catholique romaine, à toutes les Églises déjà établies ou futures en Hongrie, la création des Églises est devenue une affaire très intéressante. À tel point qu'au début des années 2010,406 Églises fonctionnaient déjà en Hongrie et elles bénéficiaient toutes de ces traitements préférentiels indépendant de leur histoire ou de leur taille.

Dans une approche juridique, l'on pourrait qualifier la constitution de ces Églises comme un abus du droit, notamment sous l'aspect du droit constitutionnel, un abus dans l'exercice de la liberté religieuse. De même, toujours sous l'aspect du droit, la création de ces Églises d'affaire comme on les appelait dans le langage courant mais aussi juridique (arrêt de la CEDH), va à l'encontre de l'ordre public ainsi sa protection nécessite une réaction de la part de l'État. Mais dans notre analyse, nous pourrons aller plus loin et voir que cette égalité générale dans le traitement des «Églises », l’usage des guillemets s'impose dans ce contexte, est évidemment préjudiciable pour les Églises traditionnelles qui ont non seulement joué un rôle particulier dans la fondation même et dans la préservation de l'État hongrois mais de plus ont subi de nombreuses pertes.

Dans ce régime extrêmement libéral où les tribunaux, certes, auraient pu mais pour une application rigoureuse de la loi, ne voulaient pas contrôler des critères de fonds et ont enregistré, même dans le cas d'un abus manifeste et une violation ainsi de l'ordre public, les «Églises » après un simple contrôle sur la réunion des conditions de forme ; les mêmes dispositions ont été appliquées et le même traitement a été garanti pour des situations très différentes. Nous arrivons ainsi devant la problématique habituelle d'une réglementation générales devant la diversité des situations, non sans oublier, que cette problématique s'affiche ici dans une matière particulièrement complexe et comme nous avons vu très sensible à plusieurs égards.

En 2010, après l'arrivée au pouvoir du parti, toujours majoritaire et toujours au gouvernement depuis, qui se présente comme conservateur et même chrétien-démocrate, une réforme constitutionnelle a été entamée. La Loi fondamentale adoptée dans le cadre de cette réforme, en 2011, se veut hongroise, non seulement en rappelant des valeurs dans son préambule, comme nous avons vu, avec des considérants particulièrement intéressants pour notre sujet, mais également par des dispositions taillées sur mesure pour la Hongrie. Ces dispositions ont fait l'objet de vives critiques notamment de la part des instances internationales qui avaient du mal à accepter des particularités, surtout après un régime constitutionnel libéral et aligné à leurs exigences, adopté au moment du changement de régime (Trócsányi, 2011, 77).

Dans le cadre de ce débat constitutionnel, les rapports entre l'État et les Églises ont également suscité des inquiétudes. La majorité parlementaire était, par contre, déterminée à mener à bien ses réformes, très particulièrement dans notre domaine d'étude. Malgré les réticences des instances internationales, relayées également par la Cour constitutionnelle hongroise, une nouvelle législation a été adoptée et pour la corroborer, même, la Loi fondamentale a été modifiée (quatrième amendement de la Loi fondamentale). Ainsi, une distinction volontaire apparaît même au niveau constitutionnel entre les communautés religieuses, pour ainsi dire, simples et les Églises traditionnelles, intégrées, ou dans la terminologie première, les Églises reconnues, notamment par une prérogative parlementaire dans la reconnaissance de ces dernières à des fins de coopération.

Il est à souligner qu'il n'était pas question de restreindre la liberté religieuse. Pour des dogmes considérés comme religieux, des convictions confessionnelles, il était toujours possible de constituer des 
communautés religieuses. Mais lorsqu'il s'agit des rapports avec l'État, notamment pour réaliser des objectifs collectifs que nous avons appelés plus simplement des missions sociales et des régimes de subvention liés à l'accomplissement de ces missions, les Églises traditionnelles, reconnues, bénéficient d'un traitement privilégié qui peut être également appliqué à d'autres communautés religieuses à la suite d'une décision adoptée dans ce sens par l'Assemblée nationale. Il est à noter qu'à nouveau, nous nous retrouvons face à des considérations à des niveaux différents, portées sur des Églises.

La problématique s'accentue lorsque le constituant et le législateur hongrois ne voulaient pas réserver ce traitement privilégié à une Église bien précise, un tel régime existe dans plusieurs États européens, mais voulait entrer dans des rapports plus étroits, conformément aux traditions multi-religieuses de la Hongrie, avec plusieurs Églises, d'ailleurs, aux caractères très différents, mais fonctionnant, toutes, d'une manière historique en Hongrie. Si l'on comprend aisément les raisons politiques, il faut pouvoir justifier sur le plan juridique aussi une telle différenciation dans le traitement des Églises. Cet exercice s'est avéré particulièrement difficile pour la Hongrie qui devait, finalement pour le résoudre, donner plusieurs définitions aux Églises.

Nous rappelons à nouveau qu'une Église, notamment dans ses rapports avec l'État, peut être considérée, d'abord, comme une institution confessionnelle et à ce titre, une séparation entre elle et l'État s'impose, mais elle peut être également vue comme une communauté traditionnelle accomplissement des missions sociales aussi pour lesquelles, surtout dans un contexte historique où elle avait subi des préjudices importants par l'action étatique pendant qu'elle avait contribué à la préservation de l'État, elle devrait compter sur le soutien étatique. S'agissant de deux choses, de deux situations distinctes, le constituant et le législateur hongrois ont décidé d'utiliser deux termes, deux noms distincts qui n'étaient pas forcément la solution la meilleure.

Dans la première législation adoptée dans ce nouveau cadre (la loi $\mathrm{n}^{\circ} \mathrm{CCVI}$ de l'an 2011), la constitution d'une communauté religieuse simple, dénommée par le législateur comme organisation menant des activités religieuses, était encore plus simple que dans le régime précédent : déjà dix personnes suffisaient lorsqu'elles réunissent autour des « mêmes principes de foi » pour demander son enregistrement auprès du tribunal compétent. Par contre, pour avoir le traitement préférentiel en matière des subventions et de fiscalité, ces communautés devaient être reconnues par l'Assemblée nationale en tant qu'Églises traditionnelles ; pour cela, elles devaient prouver un fonctionnement continu au moins centenaire à l'échelle internationale ou de deux décennies en Hongrie et sa capacité à mener des activités d'intérêt général (ibid.).

Si la décision de l'Assemblée nationale était précédée par un avis de l'Académie des sciences, elle était de prérogative parlementaire discrétionnaire. Nous pouvons aisément voir que ces nouveaux termes ne suffisaient pas forcément pour atténuer toutes les critiques. Certes, le terme général de la communauté religieuse démontre bien une certaine réalité des choses et parmi elles, nous pouvons distinguer des organisations menant des activités religieuses et des Églises traditionnelles, intégrées, mais déjà le fait que pour les premières, le terme «Église » a été retiré, peut être et sera considéré comme préjudiciable. Deuxièmement, si les critères paraissent être objectifs, et ils feront l'objet d'analyse neutre, scientifique, le pouvoir discrétionnaire de l'Assemblée nationale pouvait susciter et comme nous allons voir, ont suscité des inquiétudes.

\section{II.2. La législation actuelle à l'épreuve de la CEDH}

Ce sont justement les arguments fondant ces critiques qui ont conduit la Cour européenne des droits de l'Homme à condamner la Hongrie pour violation de la liberté religieuse et de la liberté d'association en raison de l'adoption de la législation précédemment évoquées. À la suite de cet arrêt de la Cour, la Hongrie a été contrainte d'adopter une nouvelle législation avec une catégorisation encore plus poussée quoiqu'à la lecture de l'arrêt de la Cour, on se demande si les juges ne se sont pas déjà perdus entre les catégories précédentes à une terminologie extraordinaire et difficile à traduire en langue étrangère. Néanmoins, cette nouvelle législation encore plus détaillée a déjà reçu l'approbation de différents organes 
du Conseil de l'Europe et a pu donc résoudre la question par un compromis général.

Avant d'étudier la législation toute dernière et toujours en vigueur avec ces quatre catégories : associations religieuses, Églises enregistrées, Églises reconnues et Églises « intégrées », nous souhaiterons analyser plus amplement l'arrêt en question de la Cour européenne des droits de l'Homme, car, même s'il pouvait être et était critiqué, il démarque clairement les limites que l'état actuel de l'art constitutionnel imposées aux États dans la définition de leurs rapports avec les Églises. Nous souhaiterions en accord avec les deux juges dissidents souligner, par contre, dès le départ que par cet arrêt, la Cour est allée très, peut-être, même trop loin et cet activisme de la Cour est dangereux du point de vue où il peut « compromettre la légitimité de l'ensemble du système européen de supervision des droits de l'Homme » (opinion dissidente à l'arrêt de la $\mathrm{CEDH}$ ).

La législation ci-dessus exposée a été qualifiée par les communautés religieuses qui étaient les requérants dans l'affaire, contraire à la Convention et notamment aux libertés religieuse et d'association, protégées par celle-ci parce qu'elle était, pour elles, une ingérence dans leur bon fonctionnement qui ne se justifierait pas par des buts légitimes ; elle prévoirait un traitement différencié également non justifié et introduirait une procédure déraisonnable et inéquitable. Pour le gouvernement hongrois, cette même législation est conforme à la Convention puisqu'elle n'affecterait pas l'exercice des libertés religieuse et d'association, la personnalité juridique étant garantie à toutes les communautés religieuses qui peuvent donc mener leurs activités confessionnelles.

L'argumentaire plus poussé du gouvernement est également intéressant surtout lorsqu'on le met à l'épreuve des motifs de la Cour. Il défend que la liberté religieuse ne prévoit pas un droit à des subventions étatiques, c'est au pouvoir public de décider à quelle communauté, il octroie des soutiens et garantit ainsi un traitement privilégié. Bien entendu, ce pouvoir public est limité par des exigences constitutionnelles, mais dans ce cas précis, il cherche à atteindre un but légitime qui est la protection de l'ordre public et la mesure prise n'est pas disproportionnée, notamment vu l'activité des Églises d'affaire sous le régime précédent, et la procédure prévue est raisonnée et proportionnée, notamment elle est menée sur la base des critères objectifs.

C'est justement à ce niveau que les motifs de la Cour qui finalement, encore une fois, conclut à la violation de la Convention et condamnent la Hongrie en l'obligeant non seulement à payer des amendes importantes arrêtées à la suite de négociations dures par un compromis entre l'État hongrois et ces communautés pour la plupart d'entre elles, mais aussi à modifier sa législation ; sont intéressants à étudier. La Cour, conformément à sa jurisprudence constante admet qu'une régulation par la loi dans un but légitime que peut constituer la protection de l'ordre public comme dans le cas de cette affaire, sur les Églises n'est nullement contraire à la Convention, de plus, pour l'adopter, les États ont une très large marge d'appréciation.

En même temps, elle souligne et renforce les obligations d'impartialité et de neutralité qui incombent aux États dans la définition de leurs rapports avec les Églises et qui exigent notamment que l'État n'apprécie pas la légitimité des croyances. Pour conclure à la violation de la Convention, dans cette affaire, elle met en avant le fait que par les nouvelles dénominations, l'État a retiré le nom d'Église des communautés requérantes en donnant l'impression à leurs adhérents de n'être que tolérés et la procédure de reconnaissance est trop politique avec des justifications douteuses, conduisant à une différence de traitement. Si la question des subventions était importante dans les motifs des requérants, elle ne revient qu'accessoirement dans l'arrêt (motifs de l'arrêt de la CEDH).

Encore une fois, les critiques étaient nombreuses et non uniquement en Hongrie à l'égard cet arrêt et la phrase par laquelle se termine l'opinion de deux juges dissidents, partiellement déjà citée, est devenue ainsi très connue depuis : "La Cour doit toujours garder à l'esprit que la portée des droits et des libertés garantis par la Convention n'est pas illimitée... Une expansion démesurée de la portée des dispositions matérielles de la Convention risquerait de compromettre la légitimité de l'ensemble du système européen de supervision des droits de l'Homme. » Certes, le nombre des Églises s'est diminué de 406 à 32 dans l'application de la nouvelle législation, et ainsi l'objectif de rationalisation des subventions publiques des 
Églises était atteint, d'ailleurs, en se conformant au jugement, la Hongrie a maintenu à peu près le même niveau de rationalité.

Tel que nous avons vu, la nouvelle législation adoptée à la suite de cette condamnation ne renonce pas à l'objectif initial. Sur le fondement de toutes les considérations évoquées plusieurs fois aux paragraphes précédents, une réglementation, par contre, plus complexe et certainement plus détaillée a été adoptée, dans cette forme, elle a pu être approuvée par les organes du Conseil de l'Europe, aussi. Conformément à cette loi de 2015, la Hongrie, rappelons-le, distingue quatre catégories de communautés religieuses dont trois peuvent porter désormais le nom officiel de l'Église : les associations religieuses, les Églises enregistrées, les Églises reconnues et les Églises « intégrées ». Elle a maintenu ainsi dans ce régime actuel la différence de traitement et le statut préférentiel notamment pour les Églises traditionnelles.

En guise de conclusion non seulement de ce dernier chapitre mais pour toute notre étude, sachant que notre analyse juridique ne voudrait pas se conclure, un dernier élément est à soulever qui devrait et serait très probablement encore longuement étudié non uniquement en droit constitutionnel mais avec des conséquences sur celui-ci : c'est la question des valeurs qui peuvent être constitutionnelles et qui sont sûrement issues des confessions, notamment chrétiennes. Il ne s'agit nullement d'une question religieuse ou confessionnelle proprement dites, mais de ce troisième aspect des Églises qui aurait des conséquences sur l'ensemble de l'organisation de la vie en communauté, y compris à l'échelle nationale et donc constitutionnelle. C'est la chrétienté culturelle.

Car en dehors de leurs « principes de foi » et de leurs missions sociales que les Églises en tant que communautés particulières et traditionnelles entre le niveau des personnes et le niveau de l'organisation de l'État, portent un certain nombre de valeurs qui d'une part, permet à leurs communautés respectives de se procurer une identité propre, mais qui contribue et peut, dans certains cas, avoir une position dominante dans la constitution de l'identité nationale aussi. La question n'est donc ni confessionnelle ni sociale, les personnes qui seraient des athées ou qui ne seraient pas forcément pour une prise de rôle social des Églises, peuvent néanmoins se considérer comme porteuses des éléments culturels issus du patrimoine plus large de telle ou telle Église.

Et cette problématique devient pertinente lorsque l'État décide, comme dans le cas de la Hongrie, de reprendre ces valeurs dans son organisation, y compris constitutionnelle. Les rapports à définir entre l'État et les Églises sont, à ce niveau, encore plus complexes. De nombreuses questions, pour notre étude, d'ouverture, se posent. Qui est compétent pour définir ces valeurs, autrement dit, la majorité nationale peut-elle prendre en otage les Églises, en considérant le nombre des adhérents, souvent minoritaires à cet aspect? En même temps, les Églises, peuvent-elles nier leur apport au patrimoine culturel de telle ou telle communauté nationale ? Si le droit constitutionnel moderne est adepte de la séparation entre l'État et l'Église en considérant que la dernière relève uniquement de la sphère privée des citoyens, peut-il, lui aussi, nier l'existence d'un tel apport? Enfin, que deviennent les citoyens qui seraient des adhérents des Églises à des valeurs opposées ou, dans tous les cas, très différentes de celles reprises dans l'organisation nationale ? Et enfin, quelle est la réponse à apporter lorsque dans le contexte de la mondialisation, des religions nouvelles et très différentes apparaissent ? Faut-il y voir une menace ou faut-il leur apprendre les valeurs d'autres religions ou encore, faut-il intégrer leurs nouvelles valeurs à la société ? Car, la diversité, notamment en matière religieuse et surtout, en matière des valeurs, ne connaît sûrement pas de limites.

\section{Bibliographie}

Ádám A. (2000), « Az alkotmánybíróság egyházakkal kapcsolatos határozatai », dans Bitskey B. (dir.), Tíz éves az Alkotmánybíróság, Budapest, Magyar Köztársaság Alkotmánybírósága.

Cour européenne des droits de l'Homme (2014), Arrêt du 8 avril, requêtes nº 70945/11 et aliud.

Csehi Z., Szabó I., Schanda B., Varga Zs. A. (2015), A Hármaskönyv 500. évfordulóján, Budapest, 
Pázmány Press.

Csink L., Fröhlich J. (2012), Egy Alkotmány margójára, Alkotmányelméleti és értelmezési kérdések az Alaptörvényról, Budapest, Gondalat Kiadói Kör.

Jakab A. (2011), Az új alaptörvény keletkezése és gyakorlati következményei, Budapest, HVG-ORAC.

Kárbin Á. (2008), « Egyházpolitikai küzdelmek Egerben », Egyháztörténeti Szemle, année 9, n 3.

(1990), Loi $n^{\circ}$ IV sur la liberté de conscience et religieuse et sur les Églises.

(2011), Loi $n^{\circ}$ CCVI sur la liberté de conscience et religieuse et sur le statut des Églises, des confessions et des communautés religieuses.

(2015), Loi $n^{\circ} \mathrm{C}$ sur le statut des Églises, des religions et des communautés religieuses.

Paczolay P. (2003), « Lelkiismereti és vallásszabadság », dans Halmai G. (dir.), Emberi jogok, Budapest, Osiris.

Pákozdi Cs. (2012), «Kollektív jogok és nemzetfogalom Magyarország új Alaptörvényében », dans Rixer Á. (dir.), Állam és közösség. Válogatott közjogi tanulmányok Magyarország Alaptörvénye tiszteletére, Budapest, KGRE-ÁJK.

Rajki Z. (2003), « Az állam és az egyház kapcsolatának jellemz̋o vonásai a Kádár-korszakban », Egyháztörténeti Szemle, année 3, n 2.

Schanda B. (2000), Magyar állami egyházjog, Budapest, Szent István Társulat.

Székely T. (2008), Opus pacis és a Központi Szeminárium kispapjai, Budapest, Pillanatképek.

Trócsányi L. (2011), « Magyarország Alaptörvényének létrejötte és az Alaptörvény vitatott rendelkezései », Kommentár, n 4.

Varga Zs. A. (2016), « Történeti alkotmányunk vívmányai az Alaptörvény kógens rendelkezésében », Iustum Aequum Salutare, année XII, n 4.

\section{$\underline{\text { Notes }}$}

1 La production du présent article et l'accomplissement des travaux de recherche relatifs ont été soutenus dans le cadre du projet $n^{\circ}$ EFOP-3.6.2-16-2017-00007, intitulé « Les aspects du développement d'une société intelligente, durable et inclusive : réseaux sociaux, technologiques, innovateurs dans l'emploi et dans l'économique numérique », l'auteur de l'article faisant partie en tant que jeune chercheur, du groupe de travail «Les réponses de l'État aux défis sociaux actuels ». Ce projet a été réalisé avec le soutien de l’Union européenne, cofinancé par le Fonds social européen et le budget national de Hongrie.

\section{$\underline{\text { Pour citer ce document }}$}

Peter Kruzslicz, «Varietas delectat ? Les rapports entre l'État hongrois et les Églises en Hongrie», Revue Internationale des Francophonies [En ligne], La laïcité : problématiques et pratiques dans l'espace francophone, publié le : 04/12/2020, URL : http://rifrancophonies.com/rif/index.php?id=1181. 